\title{
THE DIVISION OF JOINTLY ACQUIRED PROPERTY OF DECEASED SPOUSES IN THE EVENT OF THE DEATH OF ONE OF THEM: THE LEGAL REGULATION AND LAW ENFORCEMENT PRACTICE
}

\author{
Yanina Ya. Kail \\ Volgograd Institute of Management - Branch of Russian Presidential Academy of National Economy \\ and Public Administration, Volgograd, Russian Federation \\ Victoria A. Usanova \\ Volgograd Institute of Management - Branch of Russian Presidential Academy of National Economy \\ and Public Administration, Volgograd, Russian Federation
}

Introduction: the study of the division of jointly acquired property of spouses and inheritance of property has always been given special attention by the scientists and practitioners. Quite a lot of works are devoted to this area of legal relations. However, it is not so variable and depends on the intricacies of life that there are constantly many issues that require special research and improvement of the legal regulation. The division of jointly acquired property by the spouses at the dissolution of the marriage is regulated by the norms of family law, as well as civil law in the event of the death of one of the former spouses, who do not fully correspond to each other. In this regard, today citizens often face the problems of protecting their property rights. The purpose of the research: to reveal some aspects of the legal regulation and law enforcement practice of protecting the rights of former spouses in the division of jointly acquired property in the event of the death of one of them, and to offer suggestions to help improve the relevant rules. Methods: the methods of scientific cognition are applied together, among which the main ones are the formal-legal, system methods, analysis and synthesis. Results: it is proved that the current system of the legal regulation of division of joint property of the former spouses in the event of the death of one of them requires the improvement of the legal regulation, as laid down in the legislation, the protection of property rights is quite long and expensive, which leads to the futility of efforts. Conclusions: the law enforcement practice of protecting the property rights of former spouses in the division of jointly acquired property should be recognized as generally conforming to the established norms of law. However, the lack of the clear legal regulation of the criteria and conditions for the division of jointly acquired property in the event of opening of an inheritance after the former spouse before the expiration of the threeyear statute of limitations, leads to the situations where 2 spouses will claim the inheritance - the former and the present. This situation leads to costly conflicts that are resolved in court.

Key words: divorce, former spouses, joint property, inheritance, succession order, judicial procedure for determining shares.

Citation. Kail Ya.Ya., Usanova V.A. The Division of Jointly Acquired Property of Deceased Spouses in the Event of the Death of One of Them: The Legal Regulation and Law Enforcement Practice. Legal Concept $=$ Pravovaya paradigma, 2021, vol. 20, no. 1, pp. 105-112. (in Russian). DOI: https://doi.org/10.15688/lc.jvolsu.2021.1.16

\section{РАЗДЕЛ СОВМЕСТНО НАЖИТОГО ИМУЩЕСТВА БЫВШИХ СУПРУГОВ В СЛУЧАЕ СМЕРТИ ОДНОГО ИЗ НИХ: \\ ПРАВОВОЕ РЕГУЛИРОВАНИЕ И ПРАВОПРИМЕНИТЕЛЬНАЯ ПРАКТИКА}

\author{
Янина Яковлевна Кайль \\ Волгоградский институт управления - филиал Российской академии народного хозяйства \\ и государственной службы при Президенте РФ, г. Волгоград, Российская Федерация
}




\section{Виктория Александровна Усанова}

Волгоградский институт управления - филиал Российской академии народного хозяйства и государственной службы при Президенте РФ, г. Волгоград, Российская Федерация

Введение: исследованию раздела совместно нажитого имущества супругов и наследованию имущества всегда уделялось особое внимание ученых и практиков. Данной сфере правоотношений посвящено достаточно много работ. Однако она настолько вариативна и зависит от жизненных хитросплетений, что постоянно появляется множество вопросов, которые требуют специального исследования и совершенствования правового регулирования. Раздел совместно нажитого имущества супругами при расторжении брака регулируется нормами семейного, а также гражданского права в случае смерти одного из бывших супругов, которые не в полной мере соответствуют друг другу. В связи с этим на сегодняшний день граждане зачастую сталкиваются с проблемами защиты своих имущественных прав. Цель исследования: раскрыть некоторые аспекты правового регулирования и правоприменительной практики защиты имущественных прав бывших супругов при разделе совместно нажитого имущества в случае смерти одного из них, а также предложить вариант совершенствования соответствующих норм. Методы: применены в совокупности методы научного познания, среди которых основные - методы формально-юридический, системный, анализ и синтез. Результаты: обосновано, что действующая система правового регулирования раздела совместно нажитого имущества бывших супругов в случае смерти одного из них требует совершенствования правового регулирования, так как заложенная в действующем законодательстве схема защиты имущественных прав достаточно долгосрочная и затратная, что приводит к бессмысленности предпринимаемых усилий. Выводы: правоприменительную практику защиты имущественных прав бывших супругов при разделе совместно нажитого имущества следует признать в целом соответствующей установленным нормам права. Однако отсутствие четкого правового регулирования критериев и условий раздела совместно нажитого имущества в случае открытия наследства после бывшего супруга до истечения трехлетнего срока исковой давности, приводит к ситуациям когда на наследство будут претендовать 2 супруги(а) - бывшая(ий) и настоящая(ий). Такая ситуация приводит к затратным конфликтам, разрешаемым в судебном порядке.

Ключевые слова: расторжение брака, бывшие супруги, совместная собственность, наследование, очередность наследования, судебный порядок определения долей.

Цитирование. Кайль Я. Я., Усанова В. А. Раздел совместно нажитого имущества бывших супругов в случае смерти одного из них: правовое регулирование и правоприменительная практика // Legal Concept = Правовая парадигма. -2021. - Т. 20, № 1. - C. 105-112. - DOI: https://doi.org/10.15688/lc.jvolsu.2021.1.16

\section{Введение}

В статьях 33, 34 Семейного кодекса РФ (далее - СК РФ) закреплено, что имущественные права супругов, возникшие во время брака, являются совместными. Выдел или раздел долей в совместно нажитом имуществе супругов может быть произведен как во время брака, так и в течение трех лет после прекращения брака (ст. 38 СК РФ). Инициатором такого раздела может выступать любой из супругов. Разделить имущество можно любым способом: как судебным, так и внесудебным. Если стороны не пришли к обоюдному согласию относительно своей доли путем соглашения, то они обращаются в суд. Пресекательным сроком для раздела имущества после прекращения брака является срок в три года, однако если супруги живы, то и срок для раздела имущества может быть судом восстановлен.
Пока супруги в браке, они чаще всего, не задумываются на кого оформлять приобретаемое имущество, поскольку знают, что при его разделе каждому достанется его половина, поэтому все имущество может быть записано только на одного супруга. Пока жив этот супруг, то также не возникает проблем с разделом имущества даже в случае, если супруги стали бывшими. Проблема возникает в случае, если все или большая часть имущества оформлена только на одного супруга, а он умирает. Тогда, не успев выделить своей доли из этого имущества, переживший супруг остается наедине со своими проблемами по улаживанию имущественных отношений.

Как же быть, если брак расторгнут, но в пределах трехлетнего срока супруг, сохраняя свое право на раздел совместного имущества, не успел обратиться за ним, а один из супругов умирает и не оставляет или наоборот ос- 
тавляет завещание без учета раздела имущества с бывшим супругом(ой)?

Согласно п. 2 ст. 218 Гражданского кодекса Российской Федерации (далее ГК РФ) в случае смерти гражданина право собственности на принадлежавшее ему имущество переходит по наследству к другим лицам в соответствии с завещанием или законом согласно ст. 1111 ГК РФ.

В главе 63 ГК РФ урегулирован порядок принятия и вступления в наследство. В статьях 1142-1145 и 1148 ГК РФ с первой по восьмую очередь определен круг наследников по закону и порядок их призвания к наследованию. В основе определения круга наследников и очередности их призвания к наследованию - наличие супружеских либо родственных отношений и степень родства, а также другие обстоятельства, указанные в ГК РФ.

В первую очередь к наследованию призываются супруг, дети, родители наследодателя (ст. 1142 ГК РФ). Могут приниматься во внимание и иные заслуживающие обстоятельства у лиц, претендующих на наследство. В данный перечень не включены бывшие супруги, не успевшие разделить совместно нажитое в период брака имущество.

\section{Раздел имущества бывших супругов при наличии судебного решения \\ о разводе, не вступившего в законную силу}

Для призвания к наследованию в качестве супруга наследодателя необходим действующий статус жены или мужа. Причем, поскольку Россия является светским государством, то состояние брачных отношений может подтверждаться только свидетельством о заключении брака в органах ЗАГСа. Никакие религиозные и иные браки не дают возможности в соответствии с семейным и гражданским законодательством претендовать на принятие наследства, по крайней мере, 1-й очереди наследников. Как отмечает А.Я. Рыженков: «Государственная регистрация актов гражданского состояния устанавливается в целях охраны имущественных и личных неимущественных прав граждан, а также в интересах государства» $[11$, с. 96]. Таким образом, регистрация брака служит средством защиты имущественного права супруга. Право на наследство супруга не связывается ни с совместным проживанием, ни с ведением общего хозяйства. С.П. Гришаев указывает, что «они могут проживать в разных квартиpax, городах, а иногда и в разных странах. При этом судебная практика исходит из того, что пока брак не расторгнут, переживший супруг является наследником 1 очереди» [1]. Бывший супруг, согласно логике законодателя, не входит в указанную группу, ввиду прекращения между супругами брачных отношений к моменту открытия наследства.

Про окончание брака в п. 28 Постановления Пленума Верховного Суда РФ от 29 мая 2012 г. № 9 «О судебной практике по делам о наследовании» указано, что при разрешении вопросов об определении круга наследников первой очереди по закону судам надлежит учитывать, что в случае расторжения брака в судебном порядке бывший супруг наследодателя лишается права наследовать в указанном качестве, если соответствующее решение суда вступило в законную силу до дня открытия наследства [7].

Может, конечно, возникнуть ситуация, когда разведенный супруг (наследодатель), не разделив имущество с бывшей супругой, успеет вступить в новые брачные отношения, и тогда будет нынешняя и бывшая супруга претендовать на имущество, и обе они могли бы считаться наследниками 1 очереди. Но при этом нужно иметь в виду, что чаще всего, бывшие супруги гораздо больше успевают нажить имущества, чем супруги в новом браке, если, конечно, предыдущий брак не был краткосрочным. И соответственно общий принцип законного режима раздела совместно нажитого имущества (пополам), да и собственно договорный режим раздела совместно нажитого имущества из наследственной массы может быть весьма несправедливым по отношению к бывшей супруге(у) по сравнению с новой(ым) супругой(ом).

В случае смерти супруга до вступления в законную силу решения суда о расторжении брака, брачные отношения считаются на дату открытия наследства существующими. Это утверждение подтверждается примерами судебной практики. Решение мирового судьи о расторжении брака между Ж.А.А. и Н.Ю. Жу- 
равлевой вступило в законную силу после его смерти. При таких обстоятельствах Журавлева Н.Ю. вправе претендовать на наследство Ж.А.А. как супруга наследодателя. И как следствие суд признал Журавлеву Наталью Юрьевну как супругу наследодателя наследником по закону после смерти Ж.А.А. [9]. Эта ситуация также довольно странная. Воля супругов была выражена официально до смерти наследодателя и тот факт, что не успело пройти время - 1 месяц, суд признал ее наследницей первой очереди. А если бы успел пройти месяц, то она бы уже ей не стала. Так отчего же отталкивался законодатель при закреплении данного правила? Разница может быть всего в несколько дней: вступило или нет решение суда в законную силу?! Похожие отношения существуют в приватизации: если человек успел подать заявление - волю выразил на приватизацию, а потом умер - значит, приватизации быть. То есть можно было бы анализировать данные отношения с точки зрения аналогии закона [2, с. 330]. В рассматриваемых отношениях наследования супруг(a) волю выразил(а) на расторжение брака, но решение не вступило - то все же сохраняется право наследования 1 очереди фактически уже за бывшим супругом. И это представляется весьма странным и нелогичным.

Изучив судебную практику можно заметить, что зачастую, опрометчиво разведясь, один из супругов после открытия наследства от своего бывшего супруга пытается искусственно стать наследником первой очереди. Для этого идут в ход различные «махинации». Одной из таких уловок может быть подача необоснованных апелляционных, кассационных, надзорных и иных жалоб, после вступления (как правило) в силу судебного решения о расторжении брака.

Если суд удовлетворит жалобу, то ответчик, переживший истца в вышестоящем суде будет ссылаться на допущенные судом нижестоящей инстанции нарушения процессуального законодательства, способные стать основанием для отмены решения суда о расторжении брака, а истец, переживший ответчика, заявляет отказ от иска. При отмене решения суда по жалобе ответчика или принятии судом отказа истца от иска дело прекращается (в первой ситуации в связи со смертью сто- роны). Брачные отношения между сторонами оказываются на день открытия наследства формально существующими, и в результате «переживший супруг» призывается к наследованию по закону, причем как наследник первой очереди. Такие действия пережившей стороны судом трактуются как злоупотребление процессуальными правами. Например, показательным в данном случае является решение Саровского городского суда Нижегородской области от 18 сентября 2019 г. по делу № 2-1048/2019 [10].

Тонких А.Т. обратилась в суд с иском к Бессонову И.П., Бессонову К.С. об аннулировании актовой записи о расторжении брака и признании наследником по закону в виде обязательной доли в наследстве, указав, что между истицей и Б.П. был заключен брак отделом ЗАГС Канавинского района г. Нижнего Новгорода. Совместная жизнь с Б.П. не сложилась, летом 2009 года Б.П. обратился в суд с исковым заявлением о расторжении заключенного с истицей брака. Решением суда брак между истицей и Б.П. был расторгнут. Указанное решение вступило в законную силу 13 октября 2009 года. Свидетельство о расторжении брака истица не получала, так как после прекращения совместного проживания с Б.П. уехала из г. Саров Нижегородской области и в начале октября 2009 г. уже была зарегистрирована по новому месту жительства в г. Нижний Новгород.

Б.П. умер, на момент его смерти решение мирового судьи о расторжении брака не вступило в законную силу. Но, как следует из материалов дела, с заявлением о принятии наследства в виде обязательной доли в наследстве к нотариусу в установленный шестимесячный срок А.Т. Тонких не обращалась, в суд с исковым заявлением о восстановлении пропущенного срока для юридического принятия наследства истица Тонких А.Т. также не обращалась.

Как следует из объяснений представителя истца Тонких А.Т., в права наследства фактическим принятием наследства Тонких А.Т. не вступала, так как узнала о смерти Б.П. только в 2019 году.

Таким образом, с учетом того, что истицей не представлено относимых и допустимых доказательств фактического принятия 
наследства после смерти Б.П., суд пришел к выводу, что наследство в виде обязательной доли в наследстве Тонких А.Т. в установленный срок принято не было, вследствие чего истица не может быть признана наследником имущества Б.П., и ее исковые требования удовлетворению не подлежат. В удовлетворении исковых требований Тонких А.Т. к Бессонову И.П., Бессонову К.С., Бессонову С.П. было отказано.

Бывший супруг, по общему правилу, права на наследство не имеет, он утрачивает его с момента расторжения брака. Возможны ситуации, когда один из супругов вступает во второй брак, не расторгнув первого, и после его смерти обе супруги обращаются за получением свидетельства о праве наследство [5]. В таких случаях нотариус не должен решать, какой из двух браков является действительным, а должен предложить решить этот вопрос в суде [1]. Если в суде будет доказано, что имеет место добросовестность пережившего супруга (он не знал и не мог знать о наличии нерасторгнутого брака у своего супруга), то в судебном порядке может быть признано право на наследование доли имущества наследодателя - умершего супруга.

\section{Проблемы разделения имущества супругов, приобретенного вне брака}

Другая спорная ситуация может возникнуть в случае отсутствия наследников у бывшего супруга, при условии, что раздел совместно нажитого имущества не производился. Примером такого конфликта служит решение Кинель-Черкасского районного суда Самарская области от 28 ноября 2019 г. по делу № 2-1019/2019 [8]. Истица Живолчинская Л.П. обратилась в суд о признании права собственности на вклад в Сбербанке. В обоснование предъявленного иска указала, что умер ее бывший супруг А.В. После его смерти остался денежный вклад, хранящийся в филиале ПАО Сбербанк. Поскольку наследников имущества у умершего нет, истица просила признать право собственности на вклад за ней.

Согласно ст. 1128 ГК РФ права на денежные средства, внесенные гражданином во вклад или находящиеся на любом другом сче- те гражданина в банке, могут быть им завещаны либо в порядке, предусмотренном статьями 1124-1127 ГК РФ, либо посредством совершения завещательного распоряжения в письменной форме в том филиале банка, в котором находится спорный счет. Согласно п. 1 ст. 1152 ГК РФ для приобретения наследства наследник должен его принять.

Как вышеупомянутые нормы Гражданского кодекса РФ, так и п. 28 Постановления Пленума Верховного Суда РФ [7] указывают о возможности оформления наследственных прав именно наследниками имущества умершего, а таковой истица после смерти А.В. не является. А.В. умер, при жизни он имел реальную возможность распорядиться принадлежащим ему вкладом по своему усмотрению, включая и возможность его завещания, однако этого не сделал.

Кроме того, счет был открыт после расторжения брака с истицей, поэтому средства, находящиеся на спорном счете, являются его личной собственностью, а не совместной и не подпадают под действие ст. 256 ГК РФ. В удовлетворении исковых требований Живолчинской к администрации сельского поселения Красная Горка муниципального района Кинель-Черкасский Самарской области, третьему лицу - ПАО Сбербанк о признании права собственности на денежный вклад в порядке наследования в полном объеме было отказано.

Однако фактическое прекращение на день открытия наследства семейных отношений между супругами (без расторжения брака в установленном СК РФ порядке) не отражается на наследственных правах супругов: переживший супруг призывается к наследованию после смерти супруга как его наследник по закону первой очереди.

Вступление пережившего супруга в новый брак после смерти (объявления умершим) наследодателя не влияет на его право наследовать имущество умершего в качестве наследника первой очереди [4]. Решить вопрос о выделении доли из общего имущества супругов после развода и смерти одного из них достаточно проблематично. Исковое заявление придется предъявлять ко всем наследникам (ответчикам), имущественная масса может включать как движимое, так и недвижи- 
мое имущество. Сложности начнутся в ходе определения компетентного суда, круга лиц, установления спорных объектов и их оценки, а далее проблемы доказывания. И даже в случае вынесения решения в пользу бывшего супруга, в дальнейшем ситуация будет осложнена трудностями его исполнения. Таким образом, процесс будет длительным, дорогостоящим и, скорее всего, малоэффективным. Здесь как раз становится справедливым высказывание Эдгара Хау: «Если вы умираете, не уладив свои имущественные дела, вашими наследниками становятся адвокаты» [12].

Кроме того, как указано в определении Верховного Суда РФ от 01.09.2020 № 5-КГ2069-К2 «супруги, в том числе бывшие, вправе изменять режим общей совместной собственности имущества, нажитого в браке, соглашением с любыми, не противоречащими закону условиями, поэтому бывшие супруги вправе разделить совместное имущество мировым соглашением между собой не в равных долях» [6]. Данная возможность в случае смерти одного из бывших супругов становится призрачной и маловероятной.

Таким образом, анализ правоприменительной практики показал, что при вынесении решения о разделе имущества бывших супругов в случае смерти одного из них важнейшую роль играют сроки. Такое значение суд им придает не всегда, в том числе и при разделе совместно нажитого имущества супругов $[3$, с. 40$]$.

\section{Выводы}

Налицо коллизия двух отраслей права: согласно семейному законодательству у супруга в течение трех лет есть право предъявить иск о разделе совместно нажитого имущества, но если в этот период трехлетнего срока другой супруг умер, то наследником бывший супруг не является и из наследственного имущества не может получить супружескую долю в порядке наследования. У такого супруга есть единственная возможность обратиться к наследникам, получившим наследственное имущество и определять свою долю в этом имуществе в судебном порядке. При этом порядок реализации защиты имущественных прав пережившим бывшим супру- гом достаточно длительный и дорогостоящий, что приводит фактически к нецелесообразности реализации защитных механизмов. Считаем такое положение вещей несправедливым и предлагаем включить в перечень наследников 1 очереди бывшего супруга, который в течение 3-х летнего срока развелся, но не успел разделить совместно нажитое имущество. Такие изменения позволят упростить рассмотрение одного и того же вопроса в рамках одной отрасли права - гражданского законодательства, главы 63 ГК РФ.

Авторское исследование считаем логичным закончить предложением о внесении изменений в главу 63 ГК РФ, уточнив п. 1 ст. 1142 ГК РФ, изложив его в редакции: «Наследниками первой очереди по закону являются дети, супруг, в том числе бывший супруг, если после расторжения брака в течение трех не произошел раздел совместно нажитого имущества супругов, и родители наследодателя».

\section{СПИСОК ЛИТЕРАТУРЫ}

1. Гришаев, С. П. Постатейный комментарий к части третьей Гражданского кодекса Российской Федерации / С. П. Гришаев. - Доступ из информ.правового портала «Гарант.ру».

2. Иншакова, А. О. Аналогия закона, аналогия права и акты судебного толкования, как вспомогательные источники гражданского права / А. О. Иншакова, Н. В. Кагальницкова, И. В. Балтутите // Современная научная мысль. -2016 . - № 3. - С. 228-238.

3. Кайль, Я. Я. Выделение доли в имуществе супругов как способ защиты имущественных прав: некоторые вопросы правоприменительной практики / Я. Я. Кайль, В. А. Усанова // Современные тенденции развития частного права, исполнительного производства и способов юридической защиты : материалы VI Всерос. науч.-практ. конф. - СПб. : Санкт-Петербургский институт (филиал) ВГУЮ (РПА Минюста России), 2020. - С. 38-48.

4. Комментарий к Гражданскому кодексу Российской Федерации части третьей (постатейный) / отв. ред. Н. И. Марышева, К. Б. Ярошенко. М. : Юридическая фирма «КОНТРАКТ», 2014.

5. Определение Верховного Суда РФ № 23-кг 185 от 15.01.2019. - Электрон.текстовые дан. - Доступ из информ.-правового портала «Гарант.ру».

6. Определение Судебной коллегии по гражданским делам Верховного Суда Российской Феде- 
рации от 01.09.2020 № 5-КГ20-69-К2. - Доступ из информ.-правового портала «Гарант.ру».

7. Постановление Пленума Верховного Суда РФ от 29 мая 2012 г. № 9 «О судебной практике по делам о наследовании» // Российская газета. - 2012. 6 июня (№ 127).

8. Решение Кинель-Черкасского районного суда Самарской области от 28 ноября 2019 г. по делу № 2-1019/2019. - Электрон.текстовые дан. - Режим доступа: https://sudact.ru (дата обращения 11.11.2020).

9. Решение Кольского районного суда Мурманской области от 29 января 2020 г. по делу № 2-1710/2019. - Электрон.текстовые дан. Режим доступа: https://sudact.ru (дата обращения: 11.11.2020). - Загл. с экрана.

10. Решение Саровского городского суда Нижегородской области от 18 сентября 2019 г. по делу № 2-1048/2019. - Электрон.текстовые дан. - Режим доступа: https://sudact.ru (дата обращения: 11.11.2020). - Загл. с экрана.

11. Рыженков, А. Я. Принцип признания брака, заключенного в органах ЗАГС: проблемы теории и практики / А. Я. Рыженков // Legal Concept = Правовая парадигма. - 2020. - Т. 19, № 1.-С. 92-101.DOI: https://doi.org/10.15688/lc.jvolsu.2020.1.13.

12. Цитаты и афоризмы про наследство. - Электрон. текстовые дан. - Режим доступа: https:/citaty.su/ nasledstvo-citaty-i-aforizmy. - Загл. с экрана.

\section{REFERENCES}

1. Grishaev S.P. Postatejnyj kommentarij k chastitret'ej Grazhdanskogo kodeksa Rossijskoj Federacii [Article-by-Article Commentary to Part Three of the Civil Code of the Russian Federation]. Access from "Garant" Informational and Legal Web Portal.

2. Inshakova A.O., Kagal'nickova N.V., Baltutite I.V. Analogiya zakona, analogiya prava i akty sudebnogo tolkovaniya, kak vspomogatel'nye istochniki grazhdanskogo prava [Analogy of Law, Analogy of Law and Acts of Judicial Interpretation as Subsidiary Sources of Civil Law]. Sovremennaya nauchnaya mysl' [Modern Scientific Thought], 2016, no. 3, pp. 228-238.

3. Kajl' Ya.Ya.,Usanova V.A. Vydelenie doli v imushchestve suprugov kak sposob zashchity imushchestvennyh prav: nekotorye voprosy pravoprimenitel'noj praktiki [Allocation of a Share in the Property of Spouses as a Way to Protect Property Rights: Some Issues of Law Enforcement]. Sovremennye tendencii razvitiya chastnogo prava, ispolnitel'nogo proizvodstva i sposobov yuridicheskoj zashchity. Materialy VI vserossijskoj nauchno-prakticheskoj konferencii [Current Trends in the Development of Private Law, Enforcement Proceedings and Legal Remedies. Materials of the VI All-Russian Scientific and Practical Conference]. Saint Petersburg, SanktPeterburgskij institut (filial) VGUYU (RPA Minyusta Rossii), 2020, pp. 38-48.

4. Kommentarij $k$ Grazhdanskomu kodeksu Rossijskoj Federacii chasti tret'ej (postatejnyj) [Commentary to the Civil Code of the Russian Federation Part Three (Article-by-Article)]. Ed. by N.I. Marysheva, K.B. Yaroshenko. Moscow, Yuridicheskaya firma «KONTRAKT», 2014.

5. Opredelenie Verhovnogo Suda RF № 23-kg185 ot 15.01.2019 g. [Ruling of the Supreme Court of the Russian Federation No. 23-kg18-5 of 15.01.2019]. Access from "Garant" Informational and Legal Web Portal.

6. Opredelenie Sudebnoj kollegii po grazhdanskim delam Verhovnogo Suda Rossijskoj Federacii ot 01.09.2020 N 5-KG20-69-K2 [Ruling of the Judicial Board for Civil Cases of the Supreme Court of the Russian Federation of 01.09.2020 No. 5-KG20-69-K2]. Access from “Garant” Informational and Legal Web Portal.

7. Postanovleniya Plenuma Verhovnogo Suda RF ot 29 maya 2012 g. № 9 “O sudebnoj praktike po delam o nasledovanii" [Decision No. 9 of the Plenum of the Supreme Court of the Russian Federation of 29 May 2012 on Judicial Practice in Inheritance Cases]. Rossijskaya gazeta, 2012, June 6 (no. 127).

8. Reshenie Kinel-Cherkasskogo rajonnogo suda Samarskoj oblasti ot 28 noyabrya 2019 g. po delu № 2-1019/2019 [Decision of the KinelCherkassky District Court of the Samara Region of November 28, 2019 in Case No. 2-1019/2019]. URL: https://sudact.ru (accessed 11 November 2020).

9. Reshenie Kol'skogo rajonnogo suda Murmanskoj oblasti ot 29 yanvarya $2020 \mathrm{~g}$. po delu № 2-1710/2019 [Judgment of the Kola District Court of the Murmansk Region in case No. 2-1710/2019 Dated January 29, 2020]. URL: https://sudact.ru (accessed 11 November 2020).

10. Reshenie Sarovskogo gorodskogo suda Nizhegorodskoj oblasti ot 18 sentyabrya 2019 g. po delu № 2-1048/2019 [Decision of the Sarov City Court of Nizhny Novgorod Region Dated 18 September 2019 in Case No. 2-1048/2019]. URL: https://sudact.ru (accessed 11 November 2020).

11. RyzhenkovA.Ya. Princip priznaniya braka, zaklyuchennogo v organah ZAGS: problemyteorii i praktiki [The Principle of Recognition of Marriage Concluded in the Registry Office: The Problems of Theory and Practice]. Legal Concept, 2020, vol. 19, no. 1, pp. 92-101. DOI: https://doi.org/10.15688 /lc.jvolsu.2020.1.13.

12. Tsitaty $i$ aforizmy pro nasledstvo [Quotes and Aphorisms About Inheritance]. URL: https://citaty.su/ nasledstvo-citaty-i-aforizmy. 


\section{ВОПРОСЫ ЧАСТНОПРАВОВОГО РЕГУЛИРОВАНИЯ}

\section{Information About the Authors}

Yanina Ya. Kail, Candidate of Sciences (Jurisprudence), Associate Professor, Department of Civil Law Disciplines, Volgograd Institute of Management - Branch of Russian Presidential Academy of National Economy and Public Administration, Gagarina St, 8, 400131 Volgograd, Russian Federation, grajd@vags.ru, yanika@bk.ru, https://orcid.org/0000-0002-5116-7666

Victoria A. Usanova, Candidate of Sciences (Jurisprudence), Associate Professor, Head of the Department of Financial and Business Law, Volgograd Institute of Management - Branch of Russian Presidential Academy of National Economy and Public Administration, Gagarina St, 8, 400131 Volgograd, Russian Federation, fip@vlgr.ranepa.ru, vau_77@mail.ru, https://orcid.org/0000-0002-4071-3350

\section{Информация об авторах}

Янина Яковлевна Кайль, кандидат юридических наук, доцент кафедры гражданско-правовых дисциплин, Волгоградский институт управления - филиал Российской академии народного хозяйства и государственной службы при Президенте РФ, ул. Гагарина, 8, 400131 г. Волгоград, Российская Федерация, grajd@vags.ru, yanika@bk.ru, https://orcid.org/0000-0002-5116-7666

Виктория Александровна Усанова, кандидат юридических наук, доцент, заведующая кафедрой финансового и предпринимательского права, Волгоградский институт управления - филиал Российской академии народного хозяйства и государственной службы при Президенте РФ, ул. Гагарина, 8, 400131 г. Волгоград, Российская Федерация, fip@vlgr.ranepa.ru, vau_77@mail.ru, https://orcid.org/0000-0002-4071-3350 